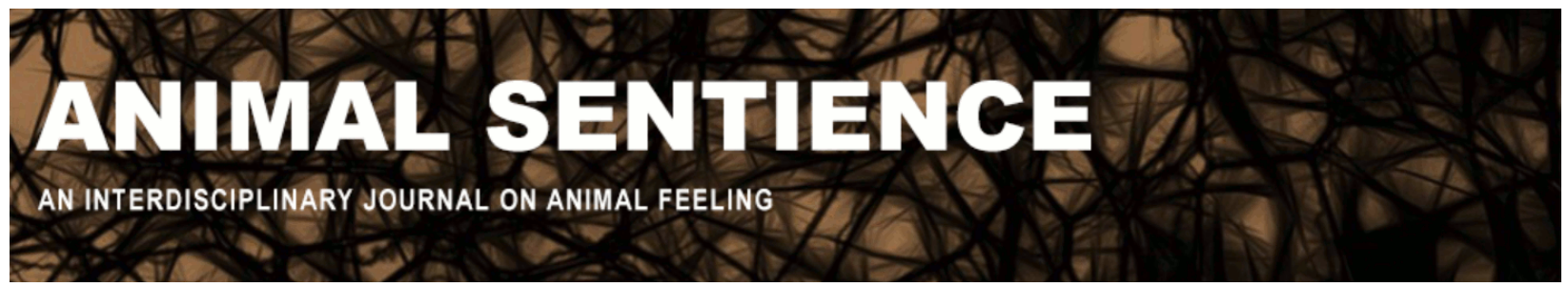

Benvenuti, Anne (2018) Good news: Humans are neither distinct nor superior. Animal Sentience 23(3)

DOI: $10.51291 / 2377-7478.1379$

Date of submission: 2019-01-23

Date of acceptance: 2019-01-31

(c)

This article has appeared in the journal Animal

Sentience, a peer-reviewed journal on animal

cognition and feeling. It has been made open access,

free for all, by WellBeing International and deposited

in the WBI Studies Repository. For more information,

please contact

wbisr-info@wellbeingintl.org.

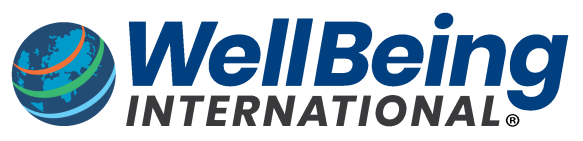

SOLUTIONS FOR PEOPLE, ANIMALS AND ENVIRONMENT 


\title{
Good news: Humans are neither distinct nor superior
}

Commentary on Chapman \& Huffman on Human Difference

\author{
Anne Benvenuti \\ Honorary Research Scholar \\ University of Winchester
}

\begin{abstract}
Chapman \& Huffman suggest that to correct our thinking about the supposed superiority of humans over other animals, we must train our reasoned investigation upon ourselves. Their thesis may usefully be viewed from within the general findings of the cognitive revolution in science, particularly findings that speak to the limits of rationality in everyday thought of humans. That we have failed - throughout a long history of scientific and philosophical thought - to ask fundamental questions about animal cognition and emotion is rooted in the fact that much of our thinking, feeling, and behaving is beyond our own immediate grasp. Scientific investigation has demonstrated that other animals are not so programmed as we assumed across a great range of behaviors. These two sets of findings should indeed change our thoughts about other animals.
\end{abstract}

Anne Benvenuti is the author of Spirit Unleashed: Reimagining Human-Animal Relations, nominated for the Pulitzer Prize in 2015. She continues to focus her interdisciplinary scholarship on humananimal relations, with particular interest in scientific explication of the qualitative dimension of experience. Website

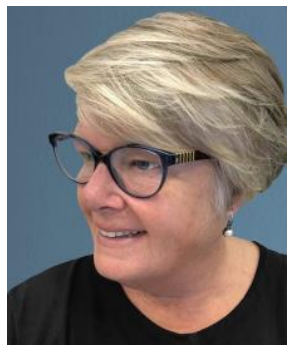

I fully concur with Chapman \& Huffman (C \& H) that to correct millennia of incorrect thinking, we must train our human power to reason and conduct our scientific investigations on our own minds. The title of their essay obliquely but accurately reflects the mistaken assumption that underlies virtually the entire past history of human thought, including scientific thought, about human-animal relations. Aristotle (350 BCE), for instance, implied that animals did not think and thus operated at a lower level of existence, without memory or forethought. Drawing upon what was by then a pervasive and entrenched meme of human distinction and superiority, Descartes (1641) declared animals to be mere machines in a mechanistic universe wherein cause and effect played out endlessly without purpose.

I add that we are both more innocent and more ignorant than $\mathrm{C} \& \mathrm{H}$ suggest because our rationality is less rational than we assume, and because our thinking is influenced by many forms of self-serving bias (Shepherd, 2008; Tavris, 2008; Taylor, 1989). C \& H's thesis must be placed within the context of the enormity of unconscious or implicit content and process in human reasoning (Damasio, 1999; Wilson, 2002; Cacioppo, 2009; Schore, 2009; Panksepp, 2012; Benvenuti, 2016). The problem is not only that we want to justify mistreatment of other animals, but that so much of our own thinking, feeling, and behaving is beyond our own 
immediate grasp. Given the relative inaccessibility of our own minds, changing deeply held constructs of culture is challenging, though possible (Wexler, 2006).

Virtually all animal behavior, including human behavior, is affectively motivated. It is our feelings that decide what we do, while our rational assessments tend to justify our behavior after the fact. Hume (1739) argued that the passions express value and should guide behavior, in contrast to Descartes (1641) and Spinoza (1677), who identified the passions as animal and sub-human. But Hume's minority position is affirmed by contemporary affective neuroscientists who note that affective systems, shared by all mammals, are biological expressions of biological values (Panksepp, 2012; Damasio, 2018).

It was the thinking of Aristotle, Descartes, Spinoza, and others, however, that led to the undergirding of the modern scientific project with a profound acceptance of the meme of human distinction and superiority. Only humans can think abstractly, it has been supposed, including the use of applied memory, mathematical reasoning, and concept formation; only humans have language; only humans use tools, or medicine; only humans organize politically; only humans have true empathy; only humans grieve and understand the finality of death; only humans have opposable thumbs and descended larynxes; only humans have self-awareness; only humans have "theory of mind," or the capacity to guess what another is thinking. Only humans have von Economo neurons. The list goes on and on, as do the refutations when these claims are submitted to experimental study (Benvenuti, 2014). All of these illustrative examples of human distinction and superiority have been empirically demonstrated to be false. To give a surprising illustration, moths remember what they learned as caterpillars (Blackiston, 2008). And some comparative neuroscientists seriously ask whether whales might be smarter than humans (Fields, 2008).

One of the most oft-cited ex-post-facto explanations for the assumption of human superiority is the notion that animals lack language capacity. But now we know that elephants communicate with their feet over distances of up to twenty miles (O'Connell-Rodwell, 2000, 2007); that prairie dog language has semantic content, grammar and syntax (Slobodchikoff, 2012); that dolphins call each other by name and recall individual voices over periods of twenty years (Bruck, 2013; King, 2013); and that songbirds share with us recursive syntactic patterning: the ability to embed clauses and phrases in a series (Gentner, 2006). All these facts indicate that other animals use communication systems that perhaps should at last be classified as language (Fitch, 2005). Slobodchikoff (2012), whose elegant experiments demonstrated the complexity of prairie dog languages, notes that most scientists had accepted two broad propositions: first that other animals behave according to inflexible genetic programming, and second that they lack self-awareness and so also lack intentions. He notes: "As a result, they [were] highly unlikely to ever set up an experiment to explore the possibility that animals have language" (Slobodchikoff, 2012).

But in keeping with the principle of evolutionary continuity, and in light of recent decades of scientific exploration of both human and animal minds, I would summarize it this way: all animals share a great many of the general features of living. Animals, including humans, have internal experiences of sensation, perception, feeling, thought, and intention (Panksepp, 2009). These internal experiences are responses to the external world we share, about which animals communicate with other animals. All animals, inclusive of humans, are members of an extended family, a notion that carries an important affective component. Yes, it is past time that 
we accept and teach this scientifically correct and affectively compelling notion, and that we allow it to motivate our behavior towards other animals. As C \& H suggest, this shift to bringing the animal Other into our circle of concern may then have ripple effects in improving the lot of humans, nonhuman animals, and ecosystems alike (Freeman, 2012; Goodman, 2012).

\section{References}

Aristotle. (c. 350 BCE) On the Soul. Translated by J.A. Smith.

Benvenuti, A. (2014) Spirit Unleashed: Reimagining Human-Animal Relations. Eugene: Cascade Books.

Benvenuti, A. (2016) Evolutionary continuity of personhood: A response to Rowlands on animal personhood. Animal Sentience 10(13).

Blackiston, D.J., Silva Casey, E. and Weiss, M.R. (2008) "Retention of Memory through Metamorphosis: Can a Moth Remember What it Learned As a Caterpillar?" PLoS One 3:3.

Bruck, J. (2013) "Decades-Long Social Memory in Bottlenose Dolphins." Proceedings of the Royal Society B: Biological Sciences, 280.

Cacioppo, J.T. and Decety, J. (2009) "What Are the Brain Mechanisms on Which Psychological Processes Are Based?" Perspectives on Psychological Science 4:1, 10-18.

Chapman, C.A. and Huffman, M.A. (2018) Why do we want to think humans are different? Animal Sentience 23(1).

Damasio, A. (2018) The Strange Order of Things: Life, Feeling, and the Making of Cultures. New York: Pantheon.

Descartes, R. (1641) Meditations on First Philosophy. Translated by J. Bennett (2010-15). Fields, R.D. (2008) "Are Whales Smarter Than We Are?" Scientific American: Mind Matters.

Fitch, W.T. (2005) "The Evolution of Language: A Comparative Review." Biology and Philosophy 20, 193-230.

Freeman, M. (2012) "Thinking and Being Otherwise: Aesthetics, Ethics, Erotics. Journal of Theoretical and Philosophical Psychology 32, 196-208.

Gentner, T.Q., Fenn, K.M., Margoliash, D. and Nusbaum, H.C. (2006) "Recursive Syntactic Pattern Learning By Songbirds." Nature 440, 1204-07.

Goodman, D.M. and Freeman, M. (2012) "Editorial: Psychology and the Other Special Issue." Journal of Theoretical and Philosophical Psychology 32, 193-95.

Hume, D. (1739-40) A Treatise on Human Nature. Edited by D.F. Norton and M.J. Norton. Oxford: Oxford University Press (2000).

King, S. and Janik, V. (2013) "Bottlenose Dolphins Can Use Learned Vocal Labels to Address Each Other." PNAS, 12853-54.

Loftus, E. and Pickrell, J.E. (1995) “The Formation of False Memories." Psychiatric Annals 25:12, 720-25.

O'Connell-Rodwell, C. (2007) "Keeping an 'Ear' to the Ground: Seismic Communication in Elephants." Physiology 22:4, 287-94.

O'Connell-Rodwell, C., Arnason, B.T. and Hart, L.A. (2000) "Seismic Properties of Asian Elephant (Elephas maximus) Vocalizations and Locomotion." Journal of the Acoustical Society of America 108:6, 3066-72. 
Panksepp, J. and Biven, L. (2012) The Archaeology of Mind. New York: Norton.

Panksepp, J. and Northoff, G. (2009) "The Trans-Species Core SELF: The Emergence of Active Cultural and Neuro-Ecological Agents through Self-Related Processing within SubcorticalCortical Midline Networks." Consciousness and Cognition 18, 193-215.

Schore, A.N. (2009) "The Paradigm Shift: The Right Brain and the Relational Unconscious."

Plenary Address, American Psychological Association, Toronto, Canada.

Sheppard, J., Malone, W., \& Sweeny, K. (2008) "Exploring Causes of the Self-Serving Bias." Social and Personality Psychology Compass 2:2, 895-908.

Slobodchikoff, C. (2012) Chasing Doctor Dolittle: Learning the Language of Animals. New York:

St. Martin's Press.

de Spinoza, B. (1677) Ethics. London: Penguin Classics (1996).

Tavris, C. and Aaronson, E. (2008) Mistakes Were Made (But Not by Me): Why We Justify Foolish Beliefs, Bad Decisions, and Hurtful Acts. New York: Mariner Books.

Taylor, S.E. and Lobel, M. (1989) "Social Comparison Activity Under Threat: Downward Evaluation and Upward Contacts." Psychological Review 96:4, 569-75.

Wexler, B.E. (2006) Brain and Culture: Neurobiology, Ideology, and Social Change. Boston: MIT Press.

Wilson, T.D. (2002) Strangers to Ourselves: Discovering the Adaptive Unconscious. New York: Harvard University Press/Bellknap. 